\title{
La política en el secreto. Reflexiones a partir de lecturas contemporáneas de Edipo rey ${ }^{l}$
}

\author{
Politics in the Secret. Reflections on \\ Contemporary Readings of Oedipus Rex.
}

\author{
Ricardo Laleff Ilieff ${ }^{2}$ \\ Universidad de Buenos Aires - CONICET (Argentina)
}

Recibido:18-04-17

Aprobado: 31-01-18

\section{Resumen}

El artículo analiza la relación entre secreto y política en Edipo rey a partir de una revisión de lecturas contemporáneas sobre dicha tragedia. Para ello, se apelará a ciertas contribuciones especializadas que permitan repensar tal vínculo en conexión con el problema del saber y del conocimiento. Luego, recuperando ciertos elementos del psicoanálisis lacaniano, se efectuará un análisis crítico de la lectura desplegada por Michel Foucault en La verdad y las formas jurídicas. Esto permitirá cifrar el problema del secreto al interior de la tensión entre hombres y dioses y como parte de la desunión entre el saber y la verdad. De este modo, se concluirá sosteniendo la presencia en Edipo rey de una severa crítica democrática a la configuración política autocrática; configuración que muestra un tipo de relación entre el secreto y la política que excede la dimensión instrumental del poder y evidencia el fundamento secreto de la dominación.

Palabras-clave: Democracia, Dominación, Foucault, Lacan, Tragedia.

\footnotetext{
${ }^{1}$ Agradezco a Fabián Ludueña, Federico Lombardía, Fernando Beresñak y Mandela Muniagurria por sus atentas lecturas.

2 (ric.lal.ilie@gmail.com). Investigador del Consejo Nacional de Investigaciones Científicas y Técnicas de la República Argentina en el Instituto de Investigaciones Gino Germani de la Facultad de Ciencias Sociales de la Universidad de Buenos Aires. Sus últimas publicaciones son: “¿Por qué Gramsci?" en Las Torres de Lucca. Revista Internacional de Filosofia Política, Universidad Complutense de Madrid, 2017; "Ni Karl Marx ni Max Weber. Carl Schmitt y la tiranía de los valores" en Bajo Palabra, Universidad Autónoma de Madrid, 2017. Política y valores en la modernidad. Un recorrido teórico-político desde la muerte de Dios nietzscheana a las tribulaciones del periodo de entreguerras. Instituto de Investigaciones Gino Germani, Universidad de Buenos Aires. (Compilador), 2017; "Politización y despolitización en el pensamiento de Carl Schmitt" en Ágora filosófica, Universidad Católica de Pernambuco, 2016; "Autonomía y acotación de lo político. Una reflexión actual a partir de Antonio Gramsci y Carl Schmitt" en Revista Argentina de Ciencia Política, EUDEBA, 2016.
} 


\begin{abstract}
The following article analyzes the relationship between secret and politics in Oedipus Rex from a review of contemporary interpretations about this tragedy. In order to do so, certain specialized contributions that could allow us to rethink such link in connection with the problem of knowledge will be introduced. Moreover, a critical analysis of Michel Foucault's interpretation of the tragedy in Truth and juridical forms will be carried out, referring to certain elements of Lacanian psychoanalysis. This will allow us to locate the problem of the secret within the tension between men and gods as well as a part of the divergence between knowledge and truth. In this regard, we will arrive to the conclusion that there is a strict democratic critique in Oedipus Rex to the autocratic regime, wich will show a particular relationship between secret and politics that goes beyond an instrumental view of power, making evident the secret basis of domination.
\end{abstract}

Key-words: Democracy, Domination, Foucault, Lacan, Tragedy.

\title{
Introducción
}

En el presente trabajo efectuaremos una lectura de Edipo rey argumentando la existencia de una importante vinculación en su trama entre el secreto y la política. Para ello, apelaremos a ciertas corrientes interpretativas del mundo contemporáneo, por lo que iniciaremos el artículo encuadrando el problema del secreto a partir de contribuciones especializadas que consideran al saber como temática propia de la historia sofocleana y a la tragedia como un discurso cargado de politicidad. Esta aclaración resulta fundamental en la medida en que, dada la magnitud y proliferación de abordajes y comentarios sobre dicha pieza y su contexto, retomaremos solo aquellos que colaboren en dar cuenta del secreto en su urdimbre argumentativa. Al efectuar tal análisis, será evidente que resulta imposible cumplir acabadamente con la empresa si no reparamos en la particular y nodal relación entre el saber humano y el saber divino.

En un segundo apartado, el análisis se concentrará en la lectura desplegada por Michel Foucault en una conferencia celebrada en la ciudad brasileña de Río de Janeiro en 1973 editada en La verdad y las formas jurídicas. Refiriéndose a las prácticas jurídicas propias de la época el pensador francés señaló el costado eminentemente político de la pieza sofocleana, ponderando, a su vez, sus implicancias en la tradición occidental posterior. Cabe señalar que si bien no es de nuestro interés polemizar sobre el marco general en el que se inscribe la lectura foucaultiana, intentaremos sí retomar críticamente su análisis sobre Edipo rey. Es que si bien su perspectiva denota una interesante inquietud política 
como clave de lectura, conduce a entender al secreto como un instrumento más del poder al igual que la religiosidad que se manifiesta en el vínculo entre dioses y hombres. Ambos elementos aparecen así cifrados en un esquema de veridicción que remarca la complementariedad para la producción de verdad. Sostendremos que observar desde otro punto de vista el problema del secreto en Edipo rey permitirá mostrar la dominación política que se enmarca en sus versos desde otras aristas. Para ello será crucial evocar ciertos presupuestos del psicoanálisis lacaniano, permitiendo, en consecuencia, ubicar la existencia de un hiato insalvable entre el saber y la verdad y entre los hombres y los dioses. Para explicitar lo enunciado, las figuras de Tiresias y Creonte serán fundamentales. A partir de allí estaremos en condiciones de sostener que en la célebre obra de Sófocles se denota una relación crucial entre el secreto y la política que va más allá de la dimensión instrumental que el primero puede oficiar para con el segundo, es decir, va más allá de sugerir que la política cuenta, como parte de su técnica y como efecto de su productividad, con el instrumento del secreto. Es que en Edipo rey la política guarda un vínculo mucho más primario con el secreto, pues la política se inscribe en el secreto y ello representa la marca de un tipo de dominación específica que la obra, como expresión fidedigna de su contexto de producción, procura criticar.

\section{Sobre el saber y el conocimiento en Edipo rey}

El protagonista de la tragedia de Sófocles sabía que había matado a un hombre en un viaje que emprendió para escapar de los vaticinios del Oráculo; sabía también que fue mediante la resolución de una adivinanza que se hizo merecedor del trono de Tebas al salvar a la ciudad del dominio de la Esfinge. Sin embargo, desconocía que ese hombre al que había asesinado era el soberano de Tebas y, más aún, que era su padre biológico. Asimismo, desconocía el hecho de que éste -de nombre Layo- procuró darle muerte poco tiempo después de nacer para así escapar de las maldiciones que lo perseguían ${ }^{3}$, y que Yocasta -quien luego sería su propia compañera de alcoba- lo había dado a luz. Edipo desconocía ciertos pormenores de la trama que lo envolvía y, al mismo tiempo, conocía otros. En ese marco, adopta una actitud activa para liberar-por segunda vez- a la ciudad de una nueva maldición que se encuentra imbricada con la primera. Por ello, la responsabilidad de Edipo para con la ciudad debe ser pensada en términos de la politicidad que detenta como gobernante. En consecuencia, el saber del que se habla en la obra está atado a la política.

\footnotetext{
${ }^{3}$ El mito cuenta que la maldición se inicia cuando Layo se enamora del joven Crisipo y decide raptarlo, lo que termina produciendo el suicidio de éste debido a la vergüenza. Pélope, padre de la víctima, impreca a Layo diciéndole que no podrá engendrar hijos o que, de suceder ello, sería asesinado por éstos. En su obra, Sófocles transforma a la maldición mítica en una verdadera profecía. 
No en vano el relato se inicia con un grupo de ancianos y jóvenes en actitud suplicante que le imploran a Edipo que solucione las calamidades que están diezmando a Tebas (par. 40) . Edipo se ve obligado así a buscar respuestas: deberá salvar a Tebas resolviendo un nuevo enigma y deberá también descubrir cuál es su propia historia personal. Pero, ambos son, en verdad, partes de una misma tarea. Por tanto, se trata de una tragedia sobre el saber de la política pero también sobre el saber del hombre como tal. ¿Qué relaciones se dan al interior de ese saber tematizado por Sófocles?

En un clásico trabajo de 1966 intitulado "On Misunderstanding the Oedipus Rex", Eric Dodds señaló que existían al menos tres interpretaciones erróneas sobre tal obra. La primera de ellas enfatizaba en las supuestas lecciones que los dioses le mostraron a Edipo debido a su incorrecto orgullo. La segunda remarcaba que en la pieza de Sófocles los humanos aparecían representados como marionetas manipuladas por seres superiores. Por último, la tercera consideraba que su hacedor no tenía ningún interés en los dioses, ya que lo motivaba una intención puramente artística. Dodds procuró rebatir tales lecturas remarcando distintos argumentos para cada una; señalando el influjo exageradamente moralizante de la primera, desestimando una idea totalizadora de destino que amparaba a la segunda o explicando, para el caso de la tercera, la indudable importancia de la religiosidad en la subjetividad de la época. Al revisar el trabajo de Dodds se hace evidente que toda interpretación sobre Edipo rey debe toparse con la exigencia de delinear el tipo de acción que emprende el personaje central de la trama y, por ende, las constelaciones de elementos que se manifiestan en ella, por ella y tras ella. En este sentido, ya sea en la interpretación moralizante, en la del destino o en la estética, los hombres aparecen situados frente al conocimiento o al desconocimiento de los límites y posibilidades de su accionar y, por tanto, frente al verdadero alcance de la potestad humana y de la divina. Ahora bien, dado que el secreto no ha sido una clave de lectura utilizada, es preciso enmarcar tal problemática en aquellos trabajos que colaboren para su indagación. Por ende, la relación entre secreto y política será exhibida primeramente a partir del problema del saber que, a su vez, pondrá de relieve el vínculo entre lo humano y lo divino 5 .

\footnotetext{
${ }^{4}$ Si bien existen numerosas ediciones de Edipo rey en habla castellana, dos son las que tomaremos como referencias: una de ellas cuenta con la traducción de Assela Alamillo (1997) y la otra de García Gual (Sófocles 2012). Partiremos de la primera y señalaremos, cuando lo creamos pertinente, divergencias con la segunda.

${ }^{5} \mathrm{Si}$ bien nuestra propuesta no estriba en un análisis etimológico o filológico, es menester señalar que en latín "secreto" es traducido como secretus que proviene, a su vez, del verbo secernere que significa "poner

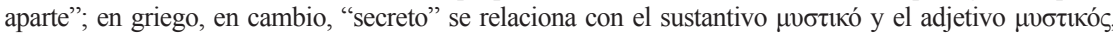
términos ambos que se vinculan con los misterios y la mística, es decir, con el universo de aquél que fue

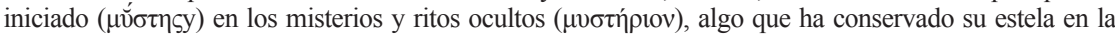
lengua de los romanos en palabras como initio (iniciar en los misterios) o consecratio (consagración a los dioses). De este modo, el problema del secreto no solo se relaciona con el del saber o el conocimiento sino también, desde su propia etimología, con la dimensión divina, cuestión clave para nuestros objetivos.
} 
En este marco comenzaremos con el trabajo de Jean-Joseph Goux, quien señaló que Edipo es "la figura prototípica del filósofo que rechaza los enigmas sagrados para instaurar la perspectiva del ser humano" (1999: 15). Apelando a la estructura de otros mitos, criticó los aspectos centrales de la lectura freudiana basada en la prohibición impuesta por el padre y el deseo parricida que reside en el inconsciente. Goux efectuó así una lectura de la tragedia bajo el problema de la iniciación y la "investidura real" (1999: 16). Esta perspectiva remarca que Edipo vence a la Esfinge con el intelecto y sin ayuda divina, lo que conlleva una forma de investidura muy distinta a la de otras héroes griegos -como Jasón o Perseo-, quienes debieron efectuar, mediante el pasaje exitoso por una prueba física que la autoridad impone, un tipo de ruptura simbólica con la influencia materna -encarnada por un monstruo femenino ${ }^{6}$ - con el objeto de que se corte el vínculo primario y se geste uno diferente con otra mujer. De esta manera, Goux señaló que Edipo rey no trata del padre freudiano que obtura el acceso de sus hijos a las mujeres, sino de un padre "lacaniano", verdadera autoridad ordenadora, que restringe la acción mediante la ley pero que también la reconduce como causa de deseo. En esta línea, Goux argumentó que, a diferencia de Freud, Lacan mostró que no existe un primer objeto de deseo perdido, sino que la madre -en tanto primer vínculo del infante- se presenta ella misma como La Cosa, encubriendo fantasmáticamente el deseo. Pero Edipo evita dar con su deseo y reconducirlo bajo los cánones de la autoridad. En consecuencia, lidia perversamente con él, quedando bajo el dominio incestuoso. De modo que Edipo funda la tradición filosófica occidental ofendiendo a Apolo, a ese dios "de la ciencia pura, del conocimiento teórico" (Goux 1999: 113). Por ello es que, para Goux, "el pecado de Edipo" concierne "de manera fundamental al conocimiento" (1999: 115). Para ser más explícitos, al rehusar la iniciación, Edipo desecha la sabiduría de los dioses. Con esta actitud arrogante, evita cualquier tipo de sacrificio físico, pues cree que "ningún enigma ha de ser divino, al punto de trascender la reflexión que puede hacer una cabeza humana" (Goux 199: 66).

Por su parte, la académica española Roció Orsi no partió de señalar el carácter filosófico de Edipo sino el de su creador, Sófocles. En este marco, argumentó que en la Antigüedad "el poeta" no era "solo un individuo sino, por encima de todo, un ciudadano" (2007: 13). En consecuencia, Orsi no solo quiso vincular la política con la tragedia, sino también la acción del poeta como una particular forma de indagación y de actividad en los asuntos políticos ${ }^{7}$. En tal virtud, concluyó que en la totalidad de la obra sofocleana, se

\footnotetext{
${ }^{6}$ Sobre el carácter femenino de la Esfinge, véase: García Gual (2012) y Kurnitsky (1992).

${ }^{7}$ Enfatizaremos sobre tal vinculación en distintos pasajes, por lo que sólo subscribiremos aquí a la importancia de "la función del discurso trágico en tanto que forma de pensamiento situada en una posición de lectura en interioridad respecto de la política democrática" (Gallego 2012: 72).
} 
cifra un juicio sobre "la imposibilidad de alcanzar un conocimiento que sirva de asidero seguro para la acción humana" (Orsi 2007: 14). En lo que concierne particularmente a la pieza sobre Edipo, Orsi decretó al "conocimiento" como su tema central, a tal punto que concibió a las intervenciones de los personajes como "la entrada y salida de informadores" (2007: 257). Desde esta óptica, Edipo es quien debe ser informado aún cuando no sea un completo ignorante. De hecho Orsi, al igual que Goux, lo describió como quien representaba el saber humano, puesto que, a través de él, Sófocles habría remarcado la importancia de "los procedimientos" (Orsi 2007: 276, $278,279)$ como validación del conocimiento. Por lo tanto, esta apreciación se conecta con el saber de la historia y de la medicina de la época, disciplinas ambas que apelaban a una suerte de empirismo cuya piedra angular consistía en la comprobación.

Ahora bien, ¿cómo pensar la necesidad del héroe por ser informado $\mathrm{y}$, al mismo tiempo, su condición de emblema del conocimiento? Primeramente hay que señalar que, para Orsi, quien sabe todo desde el principio de la obra, y así se lo expresa al propio Edipo, es el viejo adivino Tiresias $(2007: 272)^{8}$. Sin embargo, a Tiresias nadie le cree dado que su saber no entregó pruebas puesto que deriva de la adivinación y no de un método empírico. En consecuencia, los análisis de Goux y Orsi coinciden sobre este punto, pues ambos rescatan no solo la relevancia del problema del saber en la trama de Edipo sino también ubican lo que serían las futuras bases de una tradición filosófica que se estructura desde la razón. Valernos de estos aportes sobre el problema del saber y del conocimiento en Edipo rey nos permitirá encuadrar con mayores elementos la vinculación entre el secreto y la politica que se figura en sus versos. Tal intención cobrará solidez con el repaso del planteo de Foucault, ya que veremos cómo dicho pensador movilizó el problema del saber y su relación con el poder resultando, no obstante, inadecuado para ubicar la real importancia del secreto en la mencionada tragedia. Si seguimos la propuesta de Foucault, la caracterización crítica de un Edipo "ignorante" nos salvaría de ligarnos a un paradigma que desliga al poder del saber, mientras que la visión sobre un Edipo que "sabe" destacaría la dimensión productiva del poder subordinando al secreto a un lugar de marginalidad, dejándolo preso de una dimensión instrumental de la política que atenta contra aquello que creemos es posible leer en la pieza de Sófocles.

\footnotetext{
${ }^{8}$ Para un análisis sobre Tiresias, véase: Bermúdez (2000), García Gual (2011) y Loraux (2003).
} 


\section{Edipo sabe}

Foucault señaló que a "la tragedia de Edipo" había que concebirla como una "historia de búsqueda de la verdad" que evidenciaba "un procedimiento" de "las prácticas judiciales griegas de la época" (1999: 187)9. Lejos de lo anunciado en la Ilíada, Edipo rey mostraría ciertas actualizaciones con respecto al relato homérico, en la medida en que la verdad se descubre ya no mediante la "prueba" - a la que debían someterse los acusados bajo el riesgo de posible punición divina- sino a través de la presencia de testigos claves. Según dicho autor, esta práctica aparece descripta mediante el mecanismo de la "ley de las mitades" (1999: 189), cuya puesta en marcha se inicia con una suerte de rompecabezas de dos piezas que deben separarse para luego reunirse y exhibir la verdad. Un primer movimiento de este esquema se produciría en la obra cuando el dios Apolo responde que una maldición pesa sobre Tebas debido al asesinato de Layo. Es Tiresias -aquella "sombra mortal" de Apolo (Foucault 1999: 189)- quien complementa lo iniciado por la deidad expresando, ante el requerimiento insistente de Edipo, que fue él, soberano de Tebas, quien mató a Layo. Tras esta sentencia, el adivino agrega que la polis no se regenerará hasta que dicha falta no se expíe. Sófocles adelanta así el final de su pieza pero, como se sabe, la obra se encuentra lejos de concluir ${ }^{10}$. Sin embargo, para Foucault, "el juego de las mitades" está "completo": "profanación, asesinato; quién fue asesinado, quién mató" (1999: 189); pero todo se encuentra aún colocado "bajo la forma muy particular de la profecía, de la predicción de la prescripción" (Foucault 1999: 189). Se trata, como ha señalado también Orsi (2007), de la necesidad de cierta carga empírica la cual, para Foucault, sería provista por los distintos testigos. Así tras la intervención de Tiresias, Yocasta intenta tranquilizar al gobernante señalándole que, dadas las causas particulares de muerte de Layo, no podía ser él quien lo asesinó. Edipo le confiesa que esas particularidades relatadas resultan semejantes a un crimen que él cometió años atrás. Pero todavía los hechos y pormenores de la tragedia no están claros, en tanto existe cierta oquedad entre el origen y el desenlace. De todas maneras, el asesino ya tiene rostro e indirectamente ya confesó.

El pensador francés prosiguió su análisis señalando la llegada de un mensajero de Corintio al palacio, cuyo recado consiste en transmitirle al soberano tebano la muerte de Polibio, a quien éste consideraba como su ascendiente. Sin embargo, junto a tal noticia se revela que Polibio no era su

\footnotetext{
${ }^{9}$ A lo largo de su trayectoria, Foucault se mostró sensible a analizar el personaje de Edipo (véase Foucault 1996; 2009; 2011 y 2014). Aquí reponemos su conferencia en tanto en ella se ofrece su análisis más pormenorizado. Hemos elegido la traducción de Fernando Álvarez Uría y Julia Varela dado que cuenta con importantes notas aclaratorias.

${ }^{10}$ Las representaciones sobre los mitos varían, por eso los espectadores del teatro griego podían conocerlos pero sorprenderse ante las re-interpretaciones puestas en escena: "en el fondo está siempre el mito; después, la tragedia" (García Gual 2012: 10).
} 
progenitor. Un segundo personaje revela cuál es el origen de Edipo al confesar, contra su voluntad, que era vástago de Layo. Acto seguido sale a la luz que el antiguo rey había recibido la profecía de que su muerte iba a ser a manos de su descendencia; ante tal revelación, Yocasta le entregó su hijo recién nacido al antiguo sirviente que acaba de testificar para que lo depositara en el monte Citerón y así poder evitar el tan aciago vaticinio. De manera que este segundo declarante termina por rubricar la tragedia del personaje principal. En suma, "fue precisa esta reunión de los dioses y de su profeta, de Yocasta y de Edipo, del esclavo de Corinto y del esclavo de Citerón" para que "todas estas mitades, y estas mitades de mitades, se ajustasen unas a otras, se adaptaran, encajaran y reconstruyeran el perfil total de la historia" (Foucault 1999: 191). Es el testimonio de estos hombres comunes lo que termina por resolver los puntos oscuros de la historia, pues lo que han dicho "es, en el fondo, aunque de otra forma, lo que los dioses ya habían dicho" (Foucault 1999: 193). En tal virtud, el pensador francés no vio una oposición entre los declarantes y los dioses sino una complementación. Desde su óptica, Edipo rey describe así una "técnica jurídica, política y religiosa" de la época llamada por los griegos "el símbolo"; técnica que supo ser un verdadero instrumento de poder al permitir, a quien poseía "un secreto", "fracturar en dos partes un objeto cualquiera, hecho de cerámica o de otro material, guardar una de las partes y confiar la otra a alguien que debe ser portador del mensaje o atestiguar su autenticidad" (Foucault 1999: 192). En consecuencia, dicha tragedia mostraría ese mecanismo en donde el poder siempre mantiene su unidad, apelando a dispositivos que permiten su reproducción. Por esa misma operación de división es que Edipo detentaría un secreto que sale a la luz cuando las mitades se juntan. Pero Foucault no tomó en cuenta que Edipo no sabía toda la trama -que en definitiva desconocía casi toda la trama-, tampoco advirtió que el testimonio de personajes sin poder, y hasta marginales del mismo, muestran los límites del poder de Edipo ${ }^{11}$. En otras palabras, no se ocupó de precisar la importancia de estos aspectos porque su objetivo consistía en discurrir en torno a la dinámica del poder, criticando especialmente lo que él consideraba como el enfoque dominante en la tradición política occidental.

Si proseguimos a Foucault en su lectura, si efectivamente concebimos a Edipo como un tirano que condensa todo el poder y todo el saber, ¿qué sentido tendría que él mismo, como soberano, fragmentara un secreto y lo distribuyera? ¿Qué simbolizaría entonces ese hecho enfatizado por Foucault? ¿Es que lo político necesita de la fragmentación de lo que es, precisamente, la fuente de legitimidad del soberano autocrático? ¿Cómo explicar entonces,

\footnotetext{
${ }^{11}$ Para Orsi en Edipo rey se muestra claramente que "solo los que no tienen poder tienen determinado saber" (2007: 286) pues, en definitiva, es el adivino, el mensajero y los antiguos sirvientes los que anotician con pruebas empíricas sobre el verdadero origen familiar de Edipo y sobre el asesinato de Layo. De este modo, el saber de Edipo ya no puede ser explicado de manera dicotómica.
} 
que a lo largo de la obra se muestre las imposibilidades del gobernante frente a Apolo, el adivino, los testigos, Yocasta y frente al mismísimo pueblo que gobierna y al cual no puede socorrer en sus suplicas? ¿Sería Edipo un caso ejemplificador de la fragmentación del poder de una concepción del mismo entendido como objeto? Si bien es cierto que la metáfora de la partición y de la distribución de esas mitades podría apoyar una hipótesis de ese tipo, sería del todo injusto expresar que Foucault quiso decir cosa semejante cuando, más bien, procuró mostrar que Edipo debía pagar por ir en contra de ese complejo colectivo marcado por el psicoanálisis y en contra de las estructuras mismas de las relaciones de poder consagradas en Occidente. El problema de la lectura foucaultiana es que no contempló las marcas que Edipo encierra como héroe de una tragedia. Jean Pierre Vernant señaló acertadamente que "el material de la tragedia" es "el pensamiento social propio de la ciudad del siglo V" que cuestiona, "en el plano religioso y moral, los antiguos valores tradicionales" que habían sido "exaltados por la leyenda heroica", extrayendo de allí "la tragedia sus temas y sus personajes, no ya para glorificarlos, como lo hacía aún la poesía lírica, sino para cuestionarlos públicamente en nombre del nuevo ideal cívico" frente a esa "especie de asamblea o tribunal populares que constituía un teatro griego" (2002: 82) ${ }^{12}$. En otros términos, Foucault no advirtió la crítica que encerraba la tragedia como fenómeno propio de la democracia. De este modo, remarcó una y otra vez que el protagonista de la obra no era “aquél que no sabía sino, por el contrario, aquél que sabía demasiado, aquél que unía su saber y su poder de una manera condenable" y, por tal motivo, "su historia" debía "ser expulsada definitivamente de la historia" (1999: 194). De manera que el tirano Edipo -aquél hombre de excesos por su perspicacia, sabiduría, fortaleza y virilidad (Foucault 1999)- se oponía al divorcio platónico representado en República -basado en que quien gobierna no sabe y quien sabe no gobierna-. En consecuencia, el héroe Edipo respondería a la figura griega del tirano que se adueña del poder detentando "un cierto saber superior en eficacia al de los demás" (Foucault 1999: 1998). Esta postura se opone, en parte, a la de especialistas como Goux y Orsi, quienes remarcaron la línea de coincidencia entre Edipo y la filosofía posterior, inclusive la platónica. Sin adentrarnos sobre si Edipo era verdaderamente un tirano o un rey ${ }^{13}$, lo cierto es que la crítica que Sófocles desplegó queda, al seguir a Foucault, del lado del platonismo y no del de la democracia, es decir, aparece como una suerte de

\footnotetext{
${ }^{12}$ Y agrega Vernant: "en el marco de la ciudad, el hombre comienza a experimentarse a sí mismo en cuanto agente, más o menos autónomo en relación con los poderes religiosos que dominan el universo, más o menos dueño de sus actos, con más o menos influencia sobre su destino político y personal" (2002: 82).

${ }^{13}$ Goux (1999) unió la perversión del héroe con la tiranía, cuestión que avalaría una supuesta duda acerca de la legitimidad de Edipo como gobernante. Asimismo, asemejó al personaje principal con el tirano descrito en República de Platón. Orsi, en cambio, señaló que el tirano es odiado y Edipo no, por lo que desde su óptica, "se corresponde más bien" (2007: 303) con la realeza.
} 
reserva platónica al interior de una expresión democrática. Para Foucault en la propia historia de Edipo convivirían aspectos pretéritos que había que desechar y valoraciones nuevas que había que solidificar. Para ello era menester eliminar al "orientalismo" propio de la conjunción entre saber y poder y establecer la figura de un gobernante que nada sabe y que se encuentra ajeno al saber, caracterización que -según el autor-se mantendría hasta nuestros días. De allí en más, el "hombre del poder será el hombre de la ignorancia" (Foucault 1999: 201) y Edipo, que tanto podía y tanto sabía, la muestra más clara de cómo un autócrata no puede permanecer en su posición de reunión entre el saber y el poder.

Leída desde el prisma foucaultiano, la tragedia de Edipo queda reducida a una cuestión de preservación del poder, mientras que el secreto - sin un análisis específico- a un mero instrumento de la política. Si bien Foucault se refirió al vínculo entre "poder-y-saber" y "saber-y-poder" (1999: 199) destacando su dimensión simbiótica y dinámica, lo cierto es que ese binomio se vuelve recursivo al evidenciar únicamente las operaciones utilitaristas llevadas a cabo por el poder y el ocultamiento de un tipo de saber debido a su concepción de la política. De allí que, para Foucault, a Edipo no le asustaba "la idea de que podría haber matado a su padre, o al rey" puesto que temía "solamente perder su propio poder" (1999: 195). El punto sobre el cual queremos enfatizar es que la tragedia de Edipo puede ser leída a través del problema del secreto o, mejor dicho, como una obra sobre la inscripción de la política en el secreto. Sus versos muestran algo más que una relación con el secreto de características técnicas, es decir, en ella no se subordina al secreto como parte de los instrumentos que el poder puede utilizar para sus fines. Concebir al secreto de esta manera daría lugar a una larga y frondosa genealogía que respondería a lo que Michel Senellart -discípulo de Foucault- definió como una "tipología de las prácticas del secreto (2003: 45) que, ante las "breves digresiones alusivas" (Labourdette 2005), y debido al importante y heterogéneo caudal bibliográfico que sería necesario movilizar, solo alcanzarían a rozar al tema. De este modo, los más diversos usos sobre el secreto comprenderían temas tan variados como la mentira (Arendt 1996; Derrida 2002; Kant 2012; Platón 2005); la importancia del mismo en las relaciones sociales (Derrida 1998; Labourdette 2005; Simmel 1939); la dimensión teológica de los arcana imperii y su posterior vinculación con los arcana ecclesiae (Bobbio 2010, 2013; Kantorowicz 1959; Ludueña 2010; Tácito 2012); la conservación del príncipe (Maquiavelo 2010); la razón de Estado (Meinecke 2014; Schmitt 2003; Settala 1988;); el recelo del dictador de masas (Canetti 2010); la burocracia y su poder (Bobbio 2010, 2013; Weber 2014); el derecho a la información de la ciudadanía en sociedades democráticas (Bobbio 2010, 2013; Habermas 1981; Rawls 2001, 2006); los contra-poderes del delito (Bobbio 2010, 2013; Castells 1996) y hasta cuestiones de nuestros 
días como el ciber-espionaje, el secreto bancario y la privacidad tecnológica de los usuarios. Una enumeración semejante podría desplegarse mostrando los matices de estas emergencias en un estudio tipológico bien interesante, sin embargo, se seguiría enfatizando la dimensión técnica del secreto sin pensar, tal como la tragedia sofocleana parece enunciar, en otros aspectos que encierra dicha problemática. En tal virtud, nos adentraremos en Edipo rey retomando su dimensión política y ligándola al problema del conocimiento. Antes de eso deberemos efectuar una mediación en torno a la noción de verdad, para lo cual apelaremos al psicoanálisis lacaniano. Esto nos permitirá enunciar un punto de divorcio entre la autoridad divina y la de los héroes trágicos que resultará crucial para nuestra hipótesis de lectura.

\section{Lo que quiere saber Edipo}

Admitida entonces la dimensión política de la obra por la doble vía de la inscripción de la tragedia en la vida de la polis y por la materia misma de sus versos, remarcada también la importancia del conocimiento y el saber en ella -sea como mecanismo de verificación epistemológica (Orsi) o judicial (Foucault)-, o simplemente como signo característicos del discurrir filosófico de Occidente (Goux), es preciso argumentar por qué sostenemos que el psicoanálisis permite complejizar sobre el saber y la verdad -noción esta última clave para cifrar al secreto en su cabal vínculo con la política-. A diferencia de lo mentado por Foucault en su conferencia, apelar al psicoanálisis permitirá observar en Edipo rey algo más que la historia del "secreto de nuestro inconsciente" (Foucault 1999: 185). Aun cuando sea claro que la perspectiva del francés sobre el psicoanálisis no puede ser reducida a la oralidad de una comunicación -en tanto deja fuera a la casi totalidad de referencias y problemas relacionados presentes en el resto del corpus foucaultiano-, cabe remarcar que Foucault le adjudicó al psicoanálisis la autoría de presentar a Edipo como un "hombre del olvido", un "hombre del no-saber, un verdadero hombre del inconsciente" (1999: 194). Pero Foucault no se adentró sobre la escarpa de la(s) lectura(s) psicoanalítica(s) ${ }^{14}$; solo marcó su disidencia con el núcleo más esencial del aporte freudiano. Cuando expresó lo que expresó, lo hizo a tono con el marco más general de su pensamiento; marco que le exigía inscribir al psicoanálisis en una larga cadena teórico-práctica proclive a disociar el saber del poder. De este modo, se acercó al enfoque de El Anti Edipo de Gilles Deleuze y Félix Guattari, sin embargo, no prosiguió con la idea de estos autores -quienes exhibieron cómo el deseo resultaba reconducido por el psicoanálisis

\footnotetext{
${ }^{14}$ Jacques-Alain Miller (1990) señaló que Foucault le pidió que, en algún momento, le explicase el pensamiento lacaniano.
}

Araucaria. Revista Iberoamericana de Filosofía, Política y Humanidades, año 20, n 39. Primer semestre de 2018. Pp. 61-83. ISSN 1575-6823 e-ISSN 2340-2199 doi: 10.12795/araucaria.2018.i39.04 
a estructuras funcionales de la sociedad contemporánea- ${ }^{15}$. Foucault se limitó a señalar que "el complejo de Edipo" no era, en verdad, aquél mentado por el psicoanálisis, ya que éste "no se juega tanto en el plano el individual cuanto en el colectivo, no tiene que ver tanto con el deseo ni con el inconsciente, cuanto con el poder y el saber" (1999: 186).

Con el pensamiento de Lacan no solo se puede afirmar que Edipo no es para el psicoanálisis un completo ignorante sino también que Edipo mismo es si se nos permite la siguiente expresión- una suerte de arquetipo del analizante. De ese modo, el mencionado héroe trágico puede ser caracterizado como quien sabía que sabía algo pero que no sabía lo que sabía. De manera que no solo no era quien ignoraba sino quien sabía y quien -a partir de ese supuesto sabersabía lo que necesitaba saber de manera consciente ${ }^{16}$. Es por ello que Edipo - como símbolo del analizado- debía histerizarse en búsqueda de respuestas (Lacan 2012b). En este punto, aquello que fue examinado en la primera sección del artículo - esto es, cómo algunos enfoques cifraron el papel del conocimiento y el saber en la obra sofocleana- se conecta con lo que ponderamos en esta tercera sección. Ya no se trata de una lectura que pone el ojo solamente en el conocimiento de Edipo -lo que encierra el riesgo de plantear la dicotómica observación de si sabía o no-, sino más bien se alumbra un asunto que no puede ser tomado por dado, a saber, el de la noción de verdad.

A partir de tal enfoque podemos señalar que la historia de la tragedia de Sófocles muestra la vinculación no menos compleja entre el saber y la verdad. Así se entiende, por ejemplo, el motivo por el cual en uno de sus famosos seminarios, Lacan caracterizó a Hegel como el "más sublime de los histéricos" (2012b: 36) -frase que luego aparecería retomada en uno de los títulos de Slavoj Žižek (2013) - al considerarlo como el máximo representante de un discurso tendiente a anudar ambos términos. Al igual que Hegel, Edipo se histeriza de allí que sea factible recordar las figuras que nos propuso Goux de Edipo como filósofo u Orsi de un Sófocles que pone en boca de Edipo preocupaciones filosóficas-, solo que debido al registro de indagación lacaniano, se proyecta en el héroe griego la figura del analizante y se vincula así la misma operación del saber que se despliega en la terapia con la búsqueda filosófica de la verdad. De modo que, como aquél que persigue la cura a través del análisis y como un verdadero estandarte del discurso filosófico, Edipo quiso saber ardientemente la verdad pero desconocía todo lo que sabía. Sin embargo, tal como sucede con La Cosa -cuestión ya tratada por Goux-, no hay verdad para Lacan $^{17}$. No

\footnotetext{
${ }^{15}$ En torno al vínculo entre Foucault y el psicoanálisis, véase: Ayouch (2013) y Basaure (2007).

${ }^{16}$ No se trata de un juego de palabras sino de la fórmula misma que reza "el sujeto del supuesto saber" (Lacan 2012b; 2013).

17 Esta premisa ha sido retomada por toda una línea de pensamiento político contemporáneo llamada "posfundacionalismo" (Marchart 2009) y por los "lacanianos de izquierda" (Alemán 2013; Stavrakakis 2010). Los autores miembros de estas corrientes remarcan la dimensión eminentemente simbólica de la vida en sociedad, niegan toda clase de esencialismo en los
} 
solo no hay verdad porque no hay primer objeto sino también porque los tres registros del ser hablante -evidenciados en el nudo borromeo conformado por lo Real, lo Imaginario y lo Simbólico (Lacan 2012a) - denotan la dimensión eminentemente discursiva de la vida y la imposibilidad de comprender acabadamente lo Real mediante lo Simbólico o, dicho más claramente, de capturar sin fugas a lo Real mediante el lenguaje. De modo que lo Real es aquello que escapa a toda simbolización y que, al mismo tiempo, muestra los límites de toda simbolización ${ }^{18}$.

Al cifrar su aporte en ciertas fuentes lacaniana y al movilizar una lectura que echa mano de la simbología, Goux (1999) coincidiría sobre esta noción de verdad. En cambio, Orsi y Foucault plantearon algo bien diferente al respecto. Es que así, al remarcar el proceso de autonomización del saber humano, sus interpretaciones se ocuparon del impacto epistemológico y jurídico-político pero sin ir más allá del método (Orsi) o de la complementariedad al interior de los dispositivos del poder (Foucault). Asimismo, en el planteo de Goux, se observan ciertas derivas de la tensión entre el saber de los dioses y el saber humano, sin embargo, la deriva política no es retomada en su enfoque con suficiente atención, en tanto el discurso trágico es necesariamente un discurso político. En este apartado hemos visto cómo el psicoanálisis lacaniano, mediante algunos de sus presupuestos, colabora en desentrañar ciertas aristas políticas de Edipo rey, para avanzar en ello, si bien en este apartado, tal como indicara Dodds, hace falta repasar el vínculo entre hombres y dioses, empresa a la que nos abocaremos a continuación con los elementos reunidos hasta el momento ${ }^{19}$.

\section{Edipo, entre Tiresias y Creonte}

Innumerables secretos son los que aparecen enunciados en la obra de Sófocles: Yocasta guarda el secreto de que su vástago, debido a los designios del Oráculo sobre Layo, fue entregado de sus propias manos a un sirviente para que sea abandonado y muerto; este sirviente esconde, a su vez, el secreto de que su compasión lo hizo incumplir la orden real y entregar al niño a un segundo personaje -pastor de otras tierras- para que se lo llevara lejos de los alcances de tal disposición y así el niño poder conservar su vida. Por su parte, el segundo sirviente oculta el verdadero origen del recién nacido, quien fue entregado a los nobles de Corintio para su cuidado. El protagonista de la tragedia guarda

\footnotetext{
sujetos y reafirman la performatividad de las identidades políticas (Breckman 2013).

${ }^{18}$ No hay que confundir la realidad con lo Real, ya que aquí radica lo inconceptualizable, sin por ello dejar de quedar por fuera del orden simbólico (Stavrakakis 2014).

${ }^{19}$ Aunque Orsi haya destacado que "la vía hermenéutica más prometedora para abordar la tragedia de Edipo rey es, sin duda, la de tratar de desentrañar el papel que en ella desempeñan los dioses y los oráculos" (2007: 256), al centrarse en la dimensión epistemológica como clave de lectura, su enfoque no avanzó en las consecuencias políticas de la obra.
} 
también sus secretos; no solo el motivo por el cual abandona su supuesta polis -confiado nuevamente por el Oráculo- sino también el asesinato cometido en su viaje. Cuando lo recuerde, no sabrá cómo se relaciona con las tribulaciones angustiantes de la comunidad tebana. Edipo debe resolver un enigma acerca de un asesinato del pasado para levantar la maldición que pesa sobre la ciudad que gobierna y debe, en esa misma empresa que se complejiza, develar su propia historia; cuestiones ambas de una misma trama. A medida que transcurre la pieza, Edipo mantiene su curiosidad y su ímpetu por conocer lo acontecido, y ello no solo por su posición política sino también porque la historia misma de Edipo como hombre está en el centro del drama. Hacia el final de la obra, Edipo será el soberano caído en desgracia que deberá marcharse de la ciudad que salvó y dominó para acabar con la epidemia pero también el hombre que, antes de ello, se mutilará los ojos como símbolo de los límites de la especie.

Nos resta entonces desentrañar el nudo gordiano de nuestro análisis tras los elementos que hemos ido reuniendo en los anteriores apartados. Para ello deberemos detenernos en el complot que Edipo denuncia y que tiene como imputados a los personajes de Tiresias y Creonte. Como bien ha delineado García Gual, uno y otro "ofrecen sus servicios a la ciudad y ambos acuden en ayuda del rey y se enfrentan, en un determinado momento, a Edipo. Y uno y otro sobreviven a la catástrofe de Edipo" (2012: 93). De acuerdo a nuestra interpretación, la relación entre secreto y política en Edipo rey se juega entre estos dos personajes, evidenciándose en el rol que cada uno posee, el problema entre lo humano y lo divino que está en el fondo de la relación entre saber y $\operatorname{verdad}^{20}$.

Como se sabe, los personajes del adivino y de Creonte-quien fue gobernante antes de Edipo y lo será también después de él ${ }^{21}$ - reciben una imputación infundada. Recuérdese que la misma aparece poco después de comenzar la obra cuando Edipo entabla un diálogo con el adivino y éste le comunica que él mismo es el maldito de Tebas. Luego, la misma imputación será propinada a Creonte. Estas dos confrontaciones remarcan dos caras de una misma disputa: en el caso específico de la primera, la cuestión estriba en el tipo de saber, ya que el detentado por Tiresias es muy distinto al propugnado por Edipo. Sin embargo, "la obra demuestra que el saber del adivino es superior al saber del rey" (García Gual 2012: 168). En efecto, Tiresias supo siempre y, además, le informó a Edipo sobre la verdad de los hechos y la forma de expiarlos. Pero las palabras de Tiresias son tomadas por Edipo como una afrenta, quien, acto

\footnotetext{
${ }^{20}$ Tal como ha remarcado García Gual (2012), en las etimologías correspondientes de los nombres de ambos personajes se figura cierto indicio que merece ser tenido en cuenta. Es que ya en Tiresias (Teiresías) aparece cierto vínculo con la interpretación de los designios de los dioses (teírea), mientras que en Creonte (Kreon) su relación con el concepto de kratos (poder) resulta evidente y por demás sintomática

${ }^{21}$ En Antígonas Creonte es nuevamente gobernante de Tebas tras la muerte de los dos aspirantes al gobierno autocrático, Eteocles y Polinices, ambos hijos de Edipo.
}

Araucaria. Revista Iberoamericana de Filosofia, Política y Humanidades, año 20, nº 39. Primer semestre de 2018. Pp. 61-83. ISSN 1575-6823 e-ISSN 2340-2199 doi: 10.12795/araucaria.2018.i39.04 
seguido, le inquiere al adivino la denuncia de ser un conjurado. Mas Tiresias se desliga rápidamente de tal incriminación pronunciando las siguientes palabras: "aunque seas rey, se me debe dar la misma oportunidad de replicarte, al menos con palabras semejantes. También yo tengo derecho a ello, ya que no vivo sometido a ti sino a Loxias, de modo que no podré ser inscrito como seguidor de Creonte, jefe de un partido"22 (par. 410). Reafirmando así la autoridad de la deidad, Tiresias sostiene que está lejos de los dominios de Edipo y que pertenece como súbdito a Apolo. En tal virtud, no le interesan las intrigas palaciegas, lo que resultará evidente con su rápida salida de la obra.

Si bien es verdad que Edipo no tiene razones para creerle a Tiresias (Orsi 2007), no hay que olvidar el hecho de que desconfía del saber del adivino propinándole una grave e infundada imputación. Nadie hace efectivo caso a lo dicho por Tiresias porque su autoridad está devaluada. Pero, para Orsi, "no podría decirse que después de todo el ciego está más allá de la vida política, pues en la obra se hace sospechoso de participar en un complot" (2007: 290). Sin embargo, habría que señalar que, porque nadie le cree, porque él mismo no se considera ligado a la politicidad y porque no puede relacionarse con las posibles luchas de poder, Tiresias se encuentra desplazado de la política, tal como lo están los dioses. En definitiva, en Edipo rey el poder divino aparece presentado como residual. De modo que si retomamos a Goux (1999), tenemos, por un lado, que Edipo excluye el poder sacerdotal y, por otro, desde el inicio mismo de toda la tragedia, que Edipo no le confiere autoridad alguna a los dioses porque su saber ya no tiene validez. El problema central es que el poder es de Edipo pero la verdad de Tiresias o, mejor dicho, de los dioses. Habrá que esperar a todo el movimiento de testimonios y de introspección del propio héroe para que lo dicho por Tiresias tenga valor. Esto último podría avalar la lectura de Foucault y Orsi en torno a los efectos del poder y de las comprobaciones, pero también es posible observar en ello una tensión que no se resuelve y que caracteriza a la tragedia, a saber, una suerte de "impasse" (Gallego 1999: 200), pues ese mundo que se relata no es de los hombres trágicos ni de los dioses. En este sentido, recuérdese que al recibir a Tiresias (par. 300), Edipo señala el carácter iniciado del adivino y le pide ayuda como suplicante (par. 325); Tiresias se niega porque las razones de la maldición "llegarán por sí mismas" aunque "las proteja con silencio" (par. 340). Tras la insistencia de Edipo, le anuncia quién es el asesino de Layo, pero Edipo no puede entender, ya que las palabras del adivino les parecen estar en un registro "enigmático y oscuro"23 (par. 439),

\footnotetext{
${ }^{22}$ En la traducción de García Gual (Sófocles 2012) se enfatiza mucho más la ofensa recibida pero se pierde cierta dimensión de politicidad: "Aunque tú seas el rey, he de tener igual derecho a responderte. También yo tengo poder en este asunto. Porque no vivo como esclavo tuyo, sino como siervo de Loxias; de modo que no me dejaré marcar como criado de Creonte".

${ }^{23}$ García Gual (Sófocles 2012) tradujo tal pasaje señalando el carácter "enigmático y tenebroso" de las palabras de Tiresias, remarcándose así el semblante siniestro de una posible confabulación.
} 
lo que lleva a Tiresias a ensayar una respuesta cargada de ironía: “¿acaso no eres tú el más hábil por naturaleza para interpretarlo?” (par. 440). Apelando al pensamiento lacaniano, se podría decir que el saber es de los hombres y la verdad de los dioses y que Edipo rey muestra la tensión irresoluble que se juega entre esos polos. Es que Edipo puede saber pero no conoce la verdad. Se anoticiará cuando lo Real lo despedace como sujeto y no pueda, tampoco, procesarlo simbólicamente. Deberá irse de su antiguo dominio como un paria, como quien no forma parte del mundo de los hombres ni del de los dioses ${ }^{24}$.

¿Cómo se relaciona lo mencionado con el problema del secreto? Tiresias no guarda ningún secreto, en todo caso administra el saber oscuro y enigmático de los dioses que, de una forma u otra, se manifiesta para los hombres. Comunica ese saber sin que tal labor implique que los hombres confíen en él o lo entiendan cabalmente. En tal virtud, más que guardar un secreto en especial, la actitud de Tiresias se explica porque no desea pronunciar una palabra que será rechazada con oprobios hacia su persona o con desinterés hacia el propio saber divino. Dado que sus palabras no serán creídas o interpretadas con interés, la contestación entregada a Edipo se haya cargada de ironía por su afamado reconocimiento como intérprete, reconocimiento del cual el anciano carece.

En lo que concierne a Creonte, tampoco él guarda secreto alguno. Si Edipo lo ubica como posible conspirador, es porque solo él puede tener pretensión alguna de politicidad. Pero Creonte no es un confabulador, tampoco es un héroe trágico, sino el "defensor del orden" (García Gual 2012: 133). Asimismo, si el desenlace trágico de Edipo muestra la caída de una estructuración específica del poder, en la permanencia del rol de Creonte se manifiesta la perdurabilidad de la política en los asuntos humanos. Muerto Layo, Creonte gobernó la ciudad hasta que se mostró incapaz de vencer el dominio de la Esfinge, por lo cual puso a disposición el trono y la mano de su hermana viuda como premios a aquél que lograra vencer a la criatura $^{25}$. El vencedor Edipo se convertiría por un solo acto- en el soberano de Tebas y en el marido de la hermana de Creonte, es decir, en el marido de su propia madre. Develada la tragedia del héroe, es Creonte quien ocupará, una vez más, el trono de la ciudad. En este sentido, el personaje de la tragedia que mejor muestra la continuidad del poder en sus fundamentos, pero la discontinuidad por sus riesgos, no es Edipo sino Creonte: a diferencia de Tiresias -representante de un poder que no está más que en retirada del mundo-, Creonte está presente a lo largo de casi toda la pieza. Es él, de hecho, quien manifiesta más claramente la relación del secreto

\footnotetext{
${ }^{24} \mathrm{Su}$ semejanzas y diferencias con Tiresias no pueden ser más evidentes. Ambos ciegos, ambos fuera de la política, pero uno representando al poder de Apolo en la Tierra y gozando del don de la clarividencia por él entregado; el otro, maldito, carente de toda forma de videncia y sin ningún tipo de protección.

${ }^{25}$ De este modo, Creonte muestra él mismo sus limitaciones como hombre y como gobernante al admitir que escapa de sus virtudes liberar a la ciudad de su maldición y reconociendo el mérito de aquél que sí pueda hacerlo.
}

Araucaria. Revista Iberoamericana de Filosofia, Política y Humanidades, año 20, nº 39. Primer semestre de 2018. Pp. 61-83. ISSN 1575-6823 e-ISSN 2340-2199 doi: 10.12795/araucaria.2018.i39.04 
y la política en su aspecto primario. Recuérdese ese verso en donde se dirige al ya caído en desgracia Edipo diciéndole que debe entrar al palacio "porque lo más piadoso es que las deshonras familiares solo las vean y escuchen los que forman la familia" ${ }^{26}$ (par. 1430); pedido que se repite una vez más hacia el final de la pieza pero esta vez con un tono imperativo, propio de un jefe que le preocupa algo más que la cuestión del oikos - "basta ya de gemir. Entra en palacio" (par. 1510)-. Creonte asume una posición adusta, prudente, propia de hombre político tras lo que significa parte del derrumbe de su familia pero también su segundo ascenso como soberano. Su semblante es el de un gobernante que se encuentra preocupado por la mantención del poder y los actos que se dan frente a los súbditos; también por el respeto a los dioses y el bienestar de la comunidad ${ }^{27}$. En cierto sentido, el Edipo que nos pintó Foucault es, en verdad, Creonte ${ }^{28}$.

Ese repliegue de Edipo hacia el palacio - antesala del exilio del héroe trágico- es la metáfora más clara de la vinculación entre el secreto y la política. En el universo mítico de la tragedia, es en la esfera privada donde el secreto del poder se gesta y en donde asume su capacidad de propagación. La política guarda su secreto originario en el intento de dominar, porque "toda dominación que pretenda la continuidad es hasta cierto punto una dominación secreta" (2014: 1083), es decir, resulta secreta "hasta cierto punto" porque toda dominación se sustenta en el consentimiento de los dominados pero resulta secreta en la medida en que una minoría dominante, "organizada bajo una dirección superior", posee la "ventaja del pequeño número" (2014: 1082) que le permite conservar su "posición dirigente" frente a las masas dominadas (2014: 1083). Esto que fue pensado por Weber para estudiar la organización de la dominación, puede ser aplicado para el análisis de la pieza de Sófocles; sobre todo si recordamos cómo la tragedia muestra una lectura interior de la política y cómo en ella se establece una nueva relación con los mitos que denota una subjetivación diferente (Gallego 1999; 2001; 2012; 2014a; 2014b). Por ello es que, en la democracia griega, "el estatuto del héroe trágico es así confrontado con el carácter público y colectivo de las prácticas políticas atenienses" (Gallego 2014a: 141). Esta fase relatada coincidiría, entonces, con la dimensión autocrática de lo político releída críticamente desde una perspectiva democrática propia de la época del teatro griego.

\footnotetext{
${ }^{26}$ En la versión de García Gual (Sófocles 2012): "la piedad exige que los crímenes familiares solo se oigan y se vean en el seno de la familia".

${ }^{27}$ Recuérdese cómo defiende a Tiresias ante Edipo (par. 560) y cómo le demanda a los dioses instrucciones sobre qué hacer con el descubierto parricida (par. 1440).

${ }^{28}$ La politicidad adjudicada a este personaje se manifiesta también en otros pasajes de la obra como, por ejemplo, en aquél en el que el propio Creonte, desliza ante Edipo, movido por prudencia, que la respuesta recibida del Oráculo debe ser comunicada dentro del palacio y no delante del corifeo (par. 90).
}

Araucaria. Revista Iberoamericana de Filosofía, Política y Humanidades, año 20, n 39. Primer semestre de 2018 Pp. 61-83. ISSN 1575-6823 e-ISSN 2340-2199 doi: 10.12795/araucaria.2018.i39.04 
Podrán haber salido a la luz los hechos aberrantes de la familia gobernante -lo que se refuerza al recordar el mito mismo que se inicia con la maldición del linaje de Layo-, pero el poder no es del demos sino que se teje en el paredes interiores del palacio. La política en Edipo rey no puede desarrollarse enteramente a los ojos de los simples porque no es potestad de ellos sino del soberano, aún cuando también deba desplegarse delante de ellos porque la dominación es "hasta cierto punto" secreta ${ }^{29}$. De manera que no se trata de aquello que es mejor que el pueblo no sepa para protegerlo o del bueno uso de las mentiras como podría argumentarse desde una visión técnica de la política, se trata de una dimensión originaria de la política que se estructura desde un gesto privado que procura apartar a la "masa". En la reinterpretación sofocleana del mito, el secreto aparece opuesto a la democracia.

En consecuencia, no existe anudamiento alguno entre lo divino y lo humano como sí señaló Foucault, pues el género trágico no muestra la complementación sino la tensión irresoluble entre ambos polos. Acaso esto sea necesario de remarcar a partir de la comunicación y la transmisión de verdad que se muestran en la obra. El lenguaje divino es distinto al lenguaje humano y eso no deriva en que los hombres no entiendan las profecías sino en la admisión de una oquedad insalvable. Como bien señaló Vernant, "los dioses saben y dicen la verdad, pero la manifiestan formulándola en unas palabras que, al parecer de los hombres, dicen una cosa completamente distinta" (2002: 108). Allí aparece nuevamente la desconexión entre el saber y la verdad tan bien marcada por el psicoanálisis lacaniano y la consecuente imposibilidad de los hombres de condensar lo Real mediante la simbolización. La política puede producir un tipo de saber técnico pero cosa muy distinta es la verdad, potestad misma de los dioses. Edipo puede resolver el enigma de la Esfinge pero cuestión harto diferente es que Edipo supiese verdaderamente qué significaba ese enigma y las razones por las cuales esa respuesta fue la verdadera. Por eso "Edipo no entiende el discurso secreto que se va formando sin que él lo sepa, en el seno de su propio discurso" (Vernant 2002: 108) y ello no implica re-introducir la interpretación de los hombres como marionetas a la que refutó Dodds (1966). Tal como dijo acertadamente Vernant, "considerado desde el punto de vista de los hombres, Edipo es el jefe clarividente, igual a los dioses; mirado desde el punto de vista de los dioses, aparece ciego, igual a nada" (2002: 111). Se trata, entonces, de un mundo en el que los dioses aún no han muerto y en el que los héroes trágicos no pueden gobernar como las autoridades presentes en los mitos ni, mucho menos aún, como sucedía en el esquema democrático en el que se entabló dicha crítica. De allí que los héroes de la tragedia se encuentren

\footnotetext{
${ }^{29}$ Esto parece ser asumido explícitamente cuando el corifeo, en respuesta a Creonte sobre el tipo de acusación enarbolada por Edipo contra su persona, señala que no sabe la respuesta pues no conoce "lo que hacen los que tienen el poder" (par. 530).
} 
en el medio de ordenamientos, entre lo divino y lo humano; de allí que, tal como expresó Gallego, en la tragedia "los dioses no pueden ya, los hombres no pueden aun" (Gallego 1999: 200).

Edipo se encuentra entre Tiresias y Creonte; pero ni Tiresias es un dios ni Creonte es la temprana figura de la democracia que desarrolló a la tragedia. Sin embargo, el enigma de la Esfinge y el enigma de Edipo muestran una misma cosa: el mundo no es potestad de los dioses ni de los autócratas. Es que ni los dioses pueden dominar el mundo de los hombres, ni los soberanos pueden replicar sin zozobras tal dominación apelando al secreto.

\section{Consideraciones finales}

Los personajes míticos de las tragedias adoptan su fisonomía al ser reinterpretados en una tensión irresoluble entre un pasado en donde la ley fue fundada por los dioses y los semi-dioses y un presente -el del propio contexto de enunciación y representación de la Grecia antigua- que ya no admite el carácter autocrático del poder, la decisión en soledad y la imprudencia de los héroes. En la democracia la política griega pasa a ser así una cuestión de los ciudadanos y del ágora. Como hemos visto, Edipo rey muestra la estructura secreta de la dominación autocrática que se gesta en la esfera privada en el palacio y en la familia- y la exclusión, por ende, de la comunidad. Sus personajes principales no ceden en sus apuestas y aparecen presos de sus amplias potestades políticas y sus fuertes limitaciones existenciales. Podrán saber las palabras del Oráculo y -como Edipo- hasta aventurarse en la resolución de enigmas, pero su saber no es eminentemente autónomo ni suficientemente verdadero. La verdad se dice - parafraseando a Lacan- a medio decir, puesto que los Simbólico no puede dar con lo Real más que incómodamente, tangencialmente; de allí los múltiples significados que puedan encerrar, por ejemplo, los vaticinios que impulsan las acciones de los protagonistas. Pero los hombres no son, tampoco, marionetas; actúan, ejecutan, deciden. Sin embargo, como Edipo, transitan la vida ciegos. En la pieza sofocleana los dioses no ejecutan engaño alguno, más bien comunican verdades para que sean aprehensibles; lo hacen con el único instrumento que tienen los hombres para interpretar: el lenguaje. El Oráculo no engañó a Edipo ni Edipo entendió mal al Oráculo. El problema es que la simbolización no puede dar con la verdad, ya que el saber es algo bien distinto a la verdad. Pero cuando ese fracaso de la adecuación es evidente, lo Real irrumpe y produce un efecto decisivo, por ejemplo, con la muerte. ¿Cómo entender ese Real tan importante para la tragedia que es la muerte? 
La pieza de Sófocles representa -como ninguna otra de su estilo-el secreto propio de la política autocrática. El secreto es privado aún cuando sus asuntos sean públicos, y sobre ello la democracia griega se pronunció críticamente. En este sentido, todos los secretos que se relatan en Edipo rey derivan del tipo de dominación política que allí se describe, es más, sea por el lado de la dominación de la Esfinge sobre la ciudad, de la nueva maldición que hay que expiar o de la potestad de Edipo, en todos los casos es el secreto lo que anida en el fondo del gobierno. El secreto parece ser el común denominador del poder que se ejerce en las distintas etapas de la obra, casi como un atributo privado de quien lo ejerza. El simbolismo en este punto es evidente: la Esfinge dominó a la ciudad con un enigma, Edipo se convirtió en soberano al resolver ese enigma, la nueva maldición que recae en Tebas se fundamenta en un enigma. Pero resuelto el enigma del poder en cada caso, evidenciado entonces el nudo de la dominación en su modalidad específica, la configuración particular se desestructura. El poder de la Esfinge y el de Edipo son muestras de una misma estructura de poder encarnado en polos distintos, el divino y el humano, igualmente frágiles los dos, puesto que frágil es la dominación en la Tierra. En la pieza sofocleana se trata, en suma, de cómo muta el poder y de la tensión entre el poder mítico ordenador que ya no existe y el poder trágico que busca replicar formas de un pasado que tampoco existe ya. De una forma u otra, es la fragilidad de la dominación lo que se muestra, puesto que en ella-como bien señaló Weber-se juega el secreto hasta un cierto punto; el resto es consentimiento, el resto es efecto de las disputas. En tal virtud, la democracia no puede tolerar el secreto en el fondo de lo político. Es por ello que uno de sus poetas, lucidamente, enarboló críticas al respecto.

En suma, una cosa es lo que sucede cuando el secreto sale a luz y otra muy distinta allí cuando se forja: cuando sale a la luz, se desestructura el armado político coyuntural; en cambio, en su forjamiento, es la estructura de lo político la que aparece visibilizada mostrándose la soberanía del secreto, mostrándose también toda su precariedad. 


\section{Referencias bibliográficas:}

Alemán, Jorge. 2013. Conjeturas sobre una izquierda lacaniana. Buenos Aires: Grama.

Arendt, Hannah. 1996. "Verdad y Política" en Entre el Pasado y el Futuro: Ocho ensayos sobre la reflexión politica. Barcelona: Península.

—. 1998. "La mentira en política. Reflexiones sobre los Documentos del Pentágono"" en Crisis de la república. Madrid: Taurus.

Ayouch, Thamy. 2013. "Foucault a favor del psicoanálisis: verdad, veridicción, prácticas de sí” en Verba Volant. Revista de Filosofía y Psicoanálisis.

Basaure, Mauro. 2007. "El psicoanálisis como saber-poder. Sobre el funcionalismo de Foucault y su crítica al complejo de Edipo" en Signos filosóficos, vol. IX.

Bermúdez, Santiago. 2000. Tiresias, aunque ciego. Murcia: Editum.

Bobbio, Norberto. 2010. El futuro de la democracia. México: FCE.

- 2013. Democracia y secreto. México: FCE.

Breckman, Warren. 2013. Adventures of the Symbolic. Post-marxism and Radical Democracy. New York: Columbia University Press.

Canetti, Elías. 2010. Masa y poder. Madrid: Alianza.

Castells, Manuel. 1996. La era de la información. Economía, sociedad y cultura. México: Siglo XXI.

Deleuze, Gilles y Guatari, Félix. 1985. El Anti Edipo. Capitalismo y esquizofrenia. Barcelona: Paidós.

Derrida, Jacques. 1998. "Notas sobre deconstrucción y pragmatismo" en Chantal Mouffe (comp.) Deconstrucción y pragmatismo. Buenos Aires: Paidós.

- 2002. Historia de la mentira: prolegómenos. Buenos Aires: EuFyL.

Foucault, Michel. 1996. Historia de la sexualidad, vol. I. La voluntad de saber. Madrid: Siglo XXI.

—. 1999. "La verdad y las formas jurídicas" en Obras esenciales, Vol. II. Estrategias del poder. Barcelona: Paidós.

- 2009. El gobierno de sí y de los otros. Buenos Aires: Fondo de Cultura Económica.

- 2011. El coraje de la verdad. Buenos Aires: Fondo de Cultura Económica.

- 2014. Del gobierno de los vivos. Buenos Aires: Fondo de Cultura Económica.

Gallego, Julián. 1999. “El pensamiento trágico de la política democrática. El acontecimiento de una nueva justicia en la Orestía de Esquilo" en Getión. n. 17. 
- 2001. "La mirada trágica de la política: la democracia a través del teatro de Esquilo" en Gallego, Julián (editor). Prácticas religiosas, regímenes discursivos y el poder político en el mundo grecorromano. Buenos Aires: Facultad de Filosofía y Letras-Universidad de Buenos Aires.

-. 2012. "La democracia ateniense en el desierto de Lemnos. El Filoctetes de Sófocles y la política del dêmos" en Sancho Rocher, Laura; Iriarte, Ana y gallego, Julián (comps.). Lógos y Arkhé. Discurso político y autoridad en la Grecia antigua. Buenos Aires: Miño y Dávila.

_ 2014a. "El héroe trágico, el ondulante mar y la insularidad" en Dialogues d'histoire ancienne.

—. 2014b. "La crisis de la democracia ateniense a través del teatro trágico" en Argos 37.

García Gual, Carlos. 2011. Mitos, viajes héroes. Madrid: Fondo de Cultura Económica.

—. 2012. Enigmático Edipo. Mito y tragedia. Madrid: Fondo de Cultura Económica.

Habermas, Jünger. 1981. Historia y crítica de la opinión pública: La transformación estructural de la vida pública. Barcelona: Gustavo Gili.

Homero. 2010. Ilíada. Madrid: Grédos.

Kant, Inmanuel. 2004. Sobre la paz perpetua. Madrid: Alianza.

—. 2012. "Acerca de la ilegitimidad de la mentira" en ¿Hay derecho a mentir? Madrid: Técnos.

Kantorowitz, Ernst. 1959. "Secretos de Estado (Un concepto absolutista y sus tardíos orígenes medievales)" en Revista de Estudios Políticos.

Knox, Bernard. 1957. Oedipus at Thebes. Sophocles' Tragic Hero and his Times. New Haven: Yale University Press.

Kurnitsky, Horst. 1992. Edipo, un hèroe del mundo occidental. Mèxico: Siglo XXI.

Labourdette, Sergio. 1999. La estrategia del secreto. Buenos Aires: Grupo Editor Iberoamericano.

- 2005. "Secreto y poder en la vida social" en Revista Orientación y Sociedad.

Lacan, Jacques. 1991. Aun. Seminario 20. Buenos Aires: Paidós.

—. 2012a. ...o peor. Seminario 19. Buenos Aires: Paidós.

—. 2012b. El reverso del psicoanálisis. Seminario 17. Buenos Aires: Paidós.

- 2013. Los cuatro conceptos fundamentales del psicoanálisis. Seminario 11. Buenos Aires: Paidós.

Loraux, Nicole. 2003. Las experiencias de Tiresias. Lo femenino y el hombre griego. Buenos Aires: Biblos. 
Ludueña Romandini, Fabián. 2010. La comunidad de los espectros. I. Antropotecnia. Buenos Aires: Miño y Dávila.

Marchart, Oliver. 2009. El pensamiento político posfundacional. La diferencia política en Nancy, Lefort, Badiou y Laclau. Buenos Aires: Fondo de Cultura Económica.

Meinecke, Friedrich. 2014. La idea de la razón de Estado en la Edad Moderna. Madrid: Centro de Estudios Constitucionales.

Miller, Jacques-Alain. 1990. "Michel Foucault y el psicoanálisis" en AA.VV. Michel Foucault, filósofo. Barcelona: Gedisa.

Platón. 2005. República. Buenos Aires: Eudeba.

Rawls, John. 2001. El derecho de gentes y "una revisión de la idea de razón pública". Barcelona: Paidós.

-2006. El liberalismo político. México: FCE.

Segal, Charles. 1995. Sophocles' Tragic World. Divinity, Nature, Society. Cambridge: Harvard University Press.

Senellart, Michel. 2003. "Secret et publicité dans l'art gouvernemental des XVII ème et XVIII ème siècles" en Quaderni, $n^{\circ} 52$.

Settala, Ludovico. 1988. La razón de Estado. Madrid: Fondo de Cultura Económica.

Sófocles. 1997. Edipo rey [traducción de Assela Alamillo]. Madrid: Planeta de Agostini.

_. 2012. "Edipo rey" [traducción de Carlos García Gual] en García Gual, Carlos. Enigmático Edipo. Mito y tragedia. Madrid: Fondo de Cultura Económica.

Stavrakakis, Yannis. 2010. La izquierda lacaniana: psicoanálisis, teoría, política. Buenos Aires: Fondo de Cultura Económica.

- 2014. Lacan y lo político. Buenos Aires: Prometeo.

Tácito. 2012. Historias. Madrid: Grédos.

Vernant, Jean Pierre y Vidal-Naquet, Pierre. 2002. Mito y tragedia en la Grecia antigua, Vol I. Madrid: Paidós.

Weber, Max. 2014. Economía y sociedad. Buenos Aires: Fondo de Cultura Económica.

Žižek, Slavoj. 2013. El más sublime de los histéricos. Buenos Aires: Paidós. 
